\title{
Long term follow up of workers exposed to solvents
}

\author{
C Edling, K Ekberg, G Ahlborg Jr, R Alexandersson, L Barregård, L Ekenvall, L Nilsson, \\ B G Svensson
}

\begin{abstract}
Long term occupational exposure to organic solvents may cause adverse effects to the central nervous system. This collaborative study between six Swedish departments of occupational medicine examines the overall prognosis in terms of working capacity, symptoms, and psychometric test performance for individuals occupationally exposed to organic solvents. After re-analyses of the data from an initial clinical investigation of 111 men, the subjects were divided into two subgroups: one group of 65 with symptoms but no impairment on the tests and one group of 46 with toxic encephalopathy (symptoms and test impairment). At least five years after the initial examination the subjects were asked to attend a re-examination that included a structured medical interview and a psychometric investigation. The results indicate that effects on the central nervous system persist even when exposure has ceased. In the group of $\mathbf{4 6}$ more men had stopped working and were receiving sickness or early retirement pensions. This group also had reduced activity levels with regard to everyday life, leisure activities, and education or training and more neuropsychiatric symptoms. There was no support for the view that a solvent induced toxic encephalopathy is a progressive disease comparable with presenile dementia such as Alzheimer's disease or Pick's disease. If a worker was removed from exposure when he presented symptoms without signs of impair-
\end{abstract}

Departments of Occupational Medicine, University Hospital, S-751 85 Uppsala

C Edling

University Hospital, S-581 81 Linköping

K Ekberg

Medical Center Hospital, S-701 85 Örebro

G Ahlborg Jr

Karolinska Hospital, S-104 01 Stockholm

R Alexandersson

Sahlgrenska Hospital, S-412 66 Göteborg

L Barregård, L Nilsson

Södersjukhuset, S-100 64 Stockholm

L Ekenvall

University Hospital, S-221 85 Lund, Sweden

B G Svensson ment in intellectual function recovery was seen in most cases.

Since the end of the nineteenth century, organic solvents have been known to cause acute intoxication if exposure is sufficiently high. Chronic effects have also been observed in conjunction with long term exposure. Epidemiological studies in Scandinavia have indicated that occupational groups with high exposure to organic solvents were granted disability pensions as a consequence of neuropsychiatric disorders nearly twice as often as non-exposed workers. ${ }^{1-4}$ Several cross sectional studies, based on psychological testing, have shown that long term exposure to solvents may impair functions of the central nervous system, in particular, memory, concentration, and perceptual and psychomotor speed and accuracy. ${ }^{5-11}$

A World Health Organisation meeting in 1985 concluded that long term occupational exposure to organic solvents may cause adverse effects on the central and the peripheral nervous systems. ${ }^{12}$ The same conclusion was reached at a workshop on neurobehavioural effects of solvents held in the United States ${ }^{13}$ and by NIOSH. ${ }^{14}$ There are, however, some criticisms of the view that occupational inhalation of organic solvents may induce a chronic cerebral disease. ${ }^{15} 16$

Neuropsychiatric disorders due to long term exposure to solvents are now accepted as an occupational disease in the Nordic countries. Consequently, patients suffering from presumed solvent induced disease with rather non-specific symptoms constitute a large group of patients examined at occupational medicine clinics. ${ }^{17}$ The clinical picture of long term exposure to solvents is dominated by vague and non-specific symptoms and there are no specific tests. For a diagnosis of solvent induced toxic encephalopathy, according to the criteria set for insurance compensation in Sweden, the following requirements should be met $^{18}$ : long or intense exposure to solvents or both; relevant symptoms, such as increased fatigue, memory impairment, difficulties in concentration, and personality changes such as passivity; presence of pathological findings in terms of an objective measure; a relation in time between exposure and the development of symptoms and signs; and no other obvious cause of the disease.

In Sweden about 830 patients were examined in 
1986 at the occupational medicine clinics and about $14 \%$ were diagnosed as having solvent induced mild toxic encephalopathy. Although there are a few studies from Denmark, ${ }^{19}{ }^{20}$ Finland, ${ }^{2122}$ and Sweden ${ }^{23}$ describing the prognosis for patients with solvent induced neuropsychiatric disorders, the results are conflicting and there is still much to learn about the cause of the disease and its overall prognosis.

This collaborative study between six different occupational medicine clinics throughout Sweden has evaluated the overall prognosis in terms of working capacity, symptoms, and psychometric test performance. Two groups with previous exposure to solvents were followed up. One group was made up of patients diagnosed as having a solvent induced mild toxic encephalopathy; the other included patients with symptoms only. According to a recent workshop on neurobehavioural effects of solvents, the disease entities refer to type 1: symptoms only, and type 2B: symptoms and impairment in intellectual function. ${ }^{13}$ To our knowledge this is the first study where a group of patients with a diagnosed solvent induced mild toxic encephalopathy has been compared with a group of patients with the same duration of exposure to solvents and the same pattern of symptoms but without impairment in intellectual functions.

\section{Subjects}

Altogether 111 patients who had been exposed to solvents took part in the study. The patients fulfilled the following pre-established criteria for participation:

Men, not older than 70 at the follow up investigation, were accepted. This was due to lack of older age groups in the reference group for the psychometric tests.

At least 10 years of verified occupational exposure to organic solvents.

Presence of symptoms consistent with a clinical picture of organic nervous system influence.

Psychometric investigation performed at the first clinical investigation.

Reasonable exclusion of other diseases.

After re-analyses of data from an initial clinical investigation the patients were divided into two subgroups. One group of 65 men fulfilled all criteria but had none or only small impairments in the psychometric test profile and hence did not fulfil the criteria for a diagnosis of mild toxic encephalopathy (type 1). Another group of $\mathbf{4 6}$ men was diagnosed, based on symptoms and impairments in the psychometric test profile, as having a mild toxic encephalopathy (type 2B).

Six subjects in the type $2 \mathrm{~B}$ group and three in the type 1 group did not participate in the medical reexamination. One had died, one had developed Alzheimer's disease, and one had moved and could not be traced. The remaining five subjects did not wish to participate in the re-examination but some information about two of them was obtained from relatives. Three did not wish to participate in the psychometric investigation at the re-examination but completed the medical investigation.

\section{Methods}

At least five years after the initial examination the subjects were asked to attend for re-examination. This included a structured medical interview based on a protocol identical for all patients and a psychometric investigation with the TUFF battery. ${ }^{24}$

The structured interview included questions concerning duration of current and previous exposure to organic solvents. Furthermore, questions were asked about the social habits, other diseases and medication, alcohol abuse, and occurrence of 13 different neuropsychiatric symptoms. The symptoms were rated by the physician as not occurring, light to moderate, or severe. The subjects rated the subjective change in each symptom since the first examination and the physician also rated the degree of change between the two examinations in number and extent of symptoms. In most cases the same doctor performed the interview on both occasions.

The subjects were also questioned about their leisure activities. The activity areas comprised everyday and housework activities (reading newspapers, following the news on the radio or TV, housework, and sociability), hobbies, and leisure activities, and finally educational or training activities (training and membership in societies or unions). The degree of activity was rated on a three level scale; no activity, active, very active. The physician also rated the degree of change in activity level between the two examinations. Finally, the diagnosis was evaluated at the re-examination.

\section{DATA ANALYSIS}

The comparisons between first and second test results, changes in occurrence of symptoms, changes in rated activity level, and changes in performance on psychometric tests were compared by means of Student's $t$ test between group means. Paired comparisons were not used, since there was some internal loss of data. Linear correlation and multiple linear regression analysis were used to evaluate the influence of age and exposure on symptom occurrence, activity level, and test performance. The level of statistical significance was set at $5 \%$.

Before the statistical analyses, the psychometric test scores were transformed to a normally distributed stanine scale (range: $1-9$, mean $=5, S D=2$ ) to obtain age corrected scores.

\section{Results}

The characteristics of the groups are summarised in table 1. No statistically significant differences were 
Table 1 Number, age (years), duration of exposure (years), and duration until follow up (years) in the type 1 and type $2 B$ groups

\begin{tabular}{|c|c|c|c|c|}
\hline \multirow[b]{2}{*}{ Group } & \multirow[b]{2}{*}{ No } & Age & $\begin{array}{l}\text { Duration of } \\
\text { exposure }\end{array}$ & $\begin{array}{l}\text { Duration until } \\
\text { follow up }\end{array}$ \\
\hline & & $x \quad S D$ & $\begin{array}{ll}x & S D\end{array}$ & $S D$ \\
\hline $\begin{array}{l}\text { Type 1 } \\
\text { Type 2B }\end{array}$ & $\begin{array}{l}65 \\
46\end{array}$ & $\begin{array}{l}53 \pm 10 \\
56 \pm 8\end{array}$ & $\begin{array}{l}23 \pm 11 \\
26 \pm 10\end{array}$ & $\begin{array}{l}6.8 \pm 1 \\
6.7 \pm 1\end{array}$ \\
\hline
\end{tabular}

obtained between the groups in terms of mean age or average duration of exposure to solvents. The groups were similar with respect to their social status.

\section{EXPOSURE, OCCUPATIONAL ACTIVITY}

Most subjects were exposed to a mixture of organic solvents; 47 were house or industrial painters, 24 car or industrial spray painters, nine exposed mainly to petroleum fuels, and three worked with styrene. The remaining subjects came from 13 different occupations.

The mean duration of exposure at the first examination was $23 \pm 11$ years in the type 1 group and $26 \pm 10$ years in the type $2 B$ group (table 1 ). Forty one subjects had continued to work for shorter or longer durations (range: 2 months- 8 years) in solvent exposed occupations after the first examination, and at the time of the re-examination 16 were still in exposed work (table 2), 13 of whom belonged to the type 1 group. Thirty two subjects had non-exposed occupations at the re-examination. In the type 2B group the share of actively working subjects had decreased between the examinations from $48 \%$ to $26 \%$. In the type 1 group about $60 \%$ of the subjects were professionally active at both examinations.

\section{OTHER DISEASES AND USE OF MEDICATION}

At the re-examination other diseases and medication were thoroughly assessed. The most common diagnosis was hypertension ( $n=21$, eight of whom belonged to the type $2 \mathrm{~B}$ group). Of the 18 subjects

Table 2 Exposure characteristics of type 1 and type $2 B$ groups at first examination and five year follow up

\begin{tabular}{lll}
\hline & \multicolumn{2}{l}{ Groups } \\
\cline { 2 - 3 } & $\begin{array}{l}\text { Type 1 } \\
(n=65)\end{array}$ & $\begin{array}{c}\text { Type 2B } \\
(n=46)\end{array}$ \\
\hline At first examination: & 37 & 22 \\
$\quad$ Working & & \\
$\quad \begin{array}{l}\text { Disability benefit/early } \\
\text { retirement pension }\end{array}$ & 28 & 24 \\
$\begin{array}{l}\text { At re-examination: } \\
\quad \text { Working, solvent exposed }\end{array}$ & 13 & 3 \\
Working, unexposed & 24 & 8 \\
$\begin{array}{l}\text { Disability benefit/early } \\
\text { retirement pension }\end{array}$ & 20 & 32 \\
$\begin{array}{l}\text { Retired due to age } \\
\text { Dead }\end{array}$ & 3 & 2 \\
No information & 1 & -1 \\
\hline
\end{tabular}

who used psychoactive drugs-for example, sleeping pills-more or less regularly, eight belonged to the type $2 \mathrm{~B}$ group. Of the 16 subjects using beta-receptor blockers, six belonged to the type $2 \mathrm{~B}$ group. There were no differences between the groups with regard to other diseases, medication, or alcohol intake.

\section{SYMPTOMS}

The most common symptoms in both groups at the first examination were memory disturbances, difficulty in concentration, fatigue, lack of initiative, and mood effects such as irritation and depression. The type 2B group also suffered from pronounced softness.

At the re-examination the prevalence of symptoms was still greater in the type $2 B$ group than in the type 1 group. The symptoms of depression, concentration difficulties, and lack of initiative had improved in more of the subjects in the type 1 group than in the type 2B group (fig 1). The groups did not differ in degree of change in the remaining symptoms. After pooling the five core symptoms (memory, depression, concentration, lack of initiative, fatigue), more

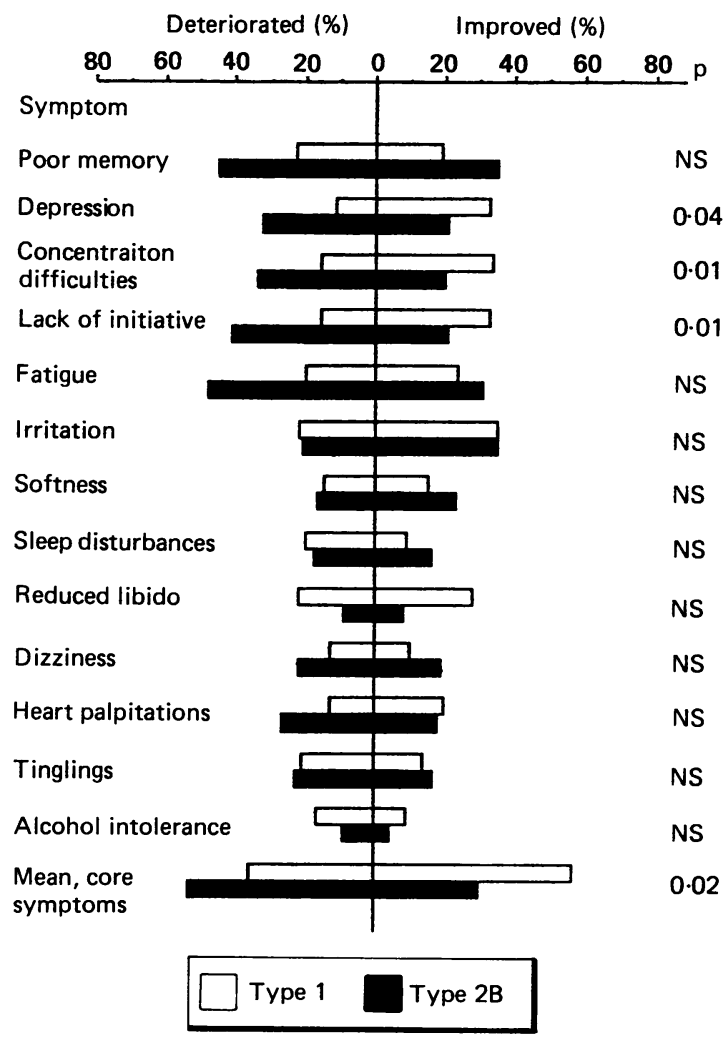

Figure 1 Changes in occurrence of symptoms at reexamination, in percentage of number of subjects in each group. $p$ Values from test of difference in symptom development between the two groups (Students' $t$ test). 
subjects in the type $2 \mathrm{~B}$ group had deteriorated and fewer subjects in this group had improved symptomatically between the examinations.

The Pearson product moment correlation coefficient between the subjective change in the occurrence of the core symptoms between the two examinations and the physicians rating was 0.64 $(p=0.001)$.

\section{ACTIVITY PATTERN}

The questions on leisure activities were pooled into three main activity areas-namely, housework, hobbies, and training. More subjects in the type 2B group had a passive activity pattern at both examinations. The groups did not differ in pattern of change of activity level between the examinations (fig 2).

Age and duration of exposure did not account for the differences in symptoms and activity levels in the two groups. Subjects who were occupationally active at the first examination had less severe symptoms than subjects who were retired or received sickness benefits $(t=2.50, p=0.01)$. They were also more active during their leisure time $(t=2,11, p=0.04)$. The occupationally active group was, however, somewhat younger (53) than the inactive group $(M=56$ years $)(t=2,23, p=0.03)$.

\section{PSYCHOMETRIC INVESTIGATION}

The comparisons between the groups on performance on psychometric tests are based on standardised scores (mean $=5, \mathrm{SD}=2$ ) to control for the possible influence of age differences between the groups.

The mean standard score of the two groups in each test appear in table 3. The differences between the groups at the first examination merely confirm the diagnostic criteria since the type 2B diagnosis depends on the outcome of the psychometric investigation. The group with the type $2 \mathrm{~B}$ diagnosis had a significantly lower performance in visuospatial ability (block design), perceptual speed (digit symbol, same numbers, dots), memory (Benton visual retention test), and psychomotor speed (cylinders), whereas the groups did not differ in the "hold tests"

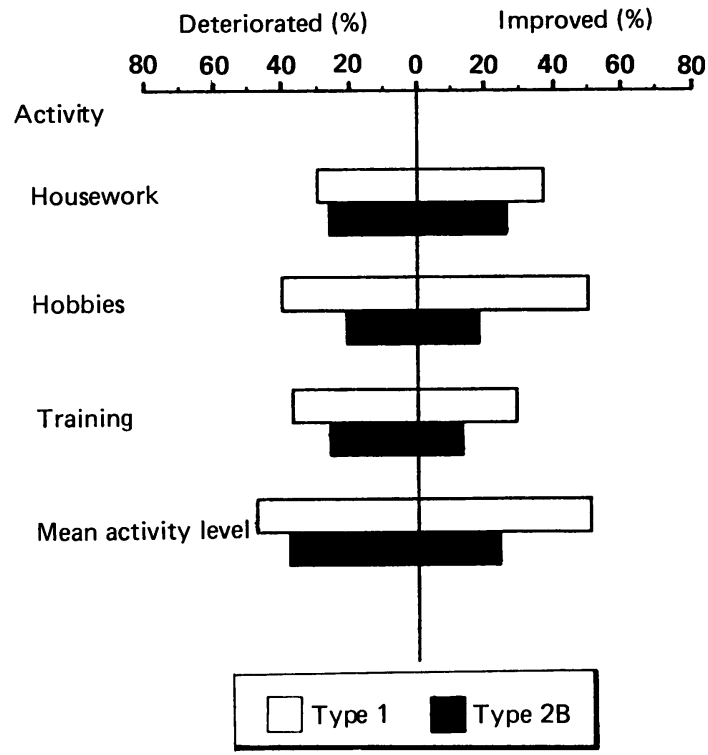

Figure 2 Change in activity level between first examination and re-examination. Percentage of number of patients in each group. No significant differences between the groups.

(synonyms and the reasoning test, figure classification).

Figure 3 shows the changes in individual stanine scores from the first to the second testing for the "hold tests" and the functional areas visuospatial ability, visual memory, perceptual ability, and psychomotor ability. More subjects in the type 2B group deteriorated in the hold tests as compared with the type 1 group; the pattern of change did not differ between the two groups for the other capacities.

The age of the patients and the duration of their exposure was not related to the differences between the groups in psychometric test performance at the two examinations.

RELATION BETWEEN THE MEASUREMENTS

Subjective change in occurrence of core symptoms

Table 3 Mean standardised scores on psychometric tests at first examination and at re-examination. $p$ Values from Student's $t$ test of differences between means

\begin{tabular}{|c|c|c|c|c|c|c|}
\hline \multirow[b]{2}{*}{ Test } & \multicolumn{3}{|c|}{ Ist examination } & \multicolumn{3}{|c|}{ Re-examination } \\
\hline & Type 1 & Type $2 B$ & $p$ & Type 1 & Type $2 B$ & $p$ \\
\hline
\end{tabular}




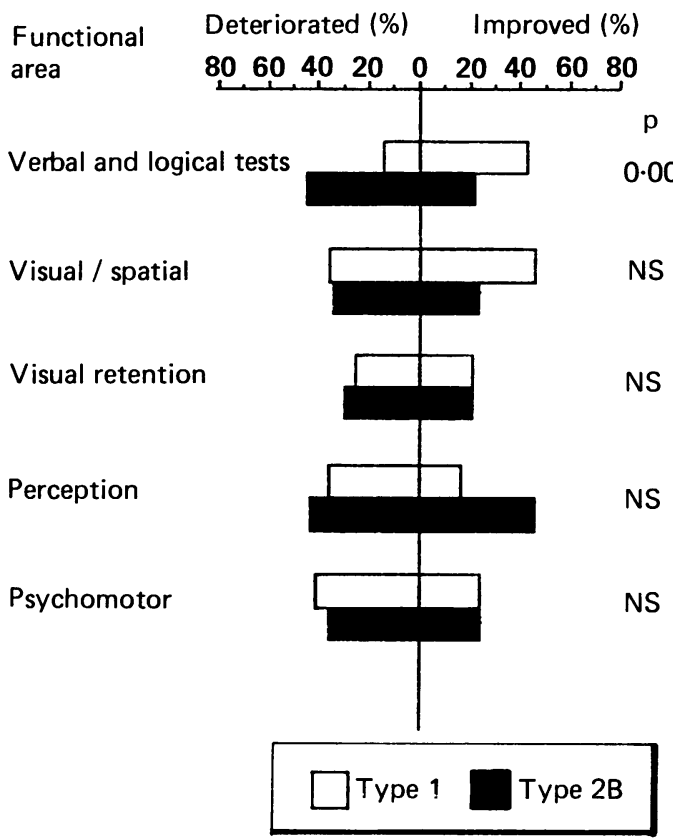

Figure 3 Changes in test performance from first to second testing, in percentage of number of subjects in each group. $p$ Values from test of difference in performance development between the two groups (Students' $t$ test).

and subjective change in activity level between the examinations were correlated $(r=0.63, p=0.001)$. Deterioration in the core symptoms between the examinations also correlated with reduced performance on the hold tests $(r=0.25, p=0.01)$, the perceptual tests $(r=0.28, p=0.01)$, and psychomotor performance $(r=0.30, p=0.01)$.

Deterioration on the hold tests and on the visual retention tests correlated with reduced activity level $(\mathrm{r}=0.18, \mathrm{p}=0.05$ and $\mathrm{r}=0.22, \mathrm{p}=0.03$ ).

Subjects with few (lower quartile) and many (upper quartile) symptoms at the first examination did not differ with respect to duration of exposure to solvents, age, activity level or performance in psychometric tests.

Subjects with a large deterioration (lower quartile) and a large improvement (upper quartile) between

Table 4 Mean stanine score on the hold tests for subjects with large deterioration (lower quartile, Q1) and with large improvement (upper quartile, $Q 4$ ) between the examinations. $p$ Values from Student's t test of differences between means

\begin{tabular}{lllllll}
\hline & $Q 1$ & & & \\
\cline { 2 - 3 } \cline { 6 - 7 } Group & $x$ & $S D$ & $x$ & $S D$ & $p$ \\
\hline Total group & 5.8 & 1.7 & & 3.7 & 1.3 & 0.000 \\
Type 1 & 5.8 & 2.1 & & 4.0 & 1.1 & NS \\
Type 2B & 5.8 & 1.6 & 2.8 & 1.4 & 0.002 \\
\hline
\end{tabular}

the examinations in the hold tests did not differ in age or duration of exposure. The deteriorating group had more symptoms at the first examination than the improving group $(t=2.04, p=0.05)$ and their symptoms occurred more between the examinations than in the other group $(t=2.32, \mathrm{p}=0.04)$. The mean activity level did not differ between the groups.

Subjects with a large deterioration in the hold tests had a significantly higher mean score on the hold tests at the first examination compared with the group with a large improvement at the follow up $(t=4.35, p=0.001)$ (table 4$)$. This regression towards the mean was more apparent in the type $2 \mathrm{~B}$ group ( $t=4.06, p=0.002)$ as compared with the type 1 group.

\section{Prognosis}

Most subjects obtained the same diagnosis at the reexamination. Twelve subjects, however, improved and changed their diagnosis from type 2B to type 1, and three subjects deteriorated and changed their diagnosis from type 1 to type $2 \mathrm{~B}$ at the second examination (fig 4).

The subjects were divided into subgroups according to the stability of diagnosis. In the statistical analysis the group which obtained a type $2 \mathrm{~B}$ diagnosis at both examinations (type 2B-type 2B) was compared with the group that obtained a type 1 diagnosis at both examinations (type 1-type 1). The type 1-type 2B group and the type 2B-type 1 group were too small to be included in the statistical analysis.

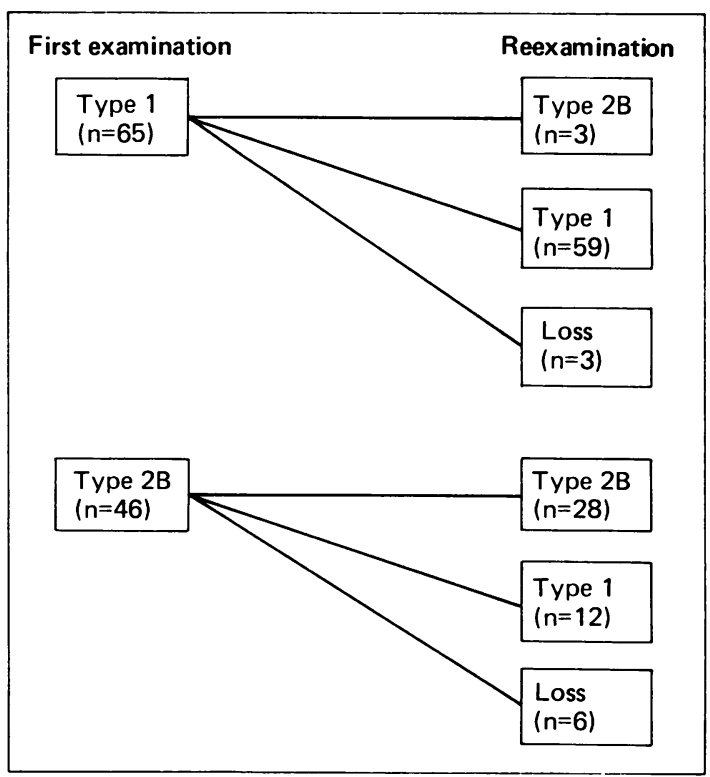

Figure 4 Distribution of subjects in the type 1 and type $2 B$ groups according to diagnosis at the examinations. 


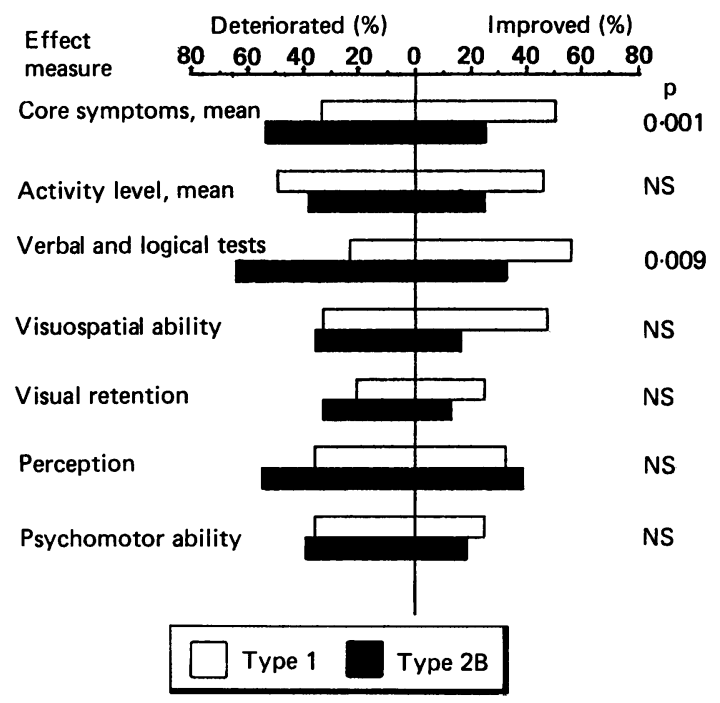

Figure 5 Changes in symptoms, activity level, and test performance between first examination and re-examination in subgroups type 2B-type 2B, type 1-type 1. Numbers given are per cent of subjects in each group. $p$ Values from Students' $t$ test, of differences between the type $2 B$-type $2 B$ group, and the type 1-type 1 group.

\section{SYMPTOMS}

The number of symptoms remained stable in all four groups at the re-examination. The type 2B-type 2B group had a fairly extensive pattern of symptoms at both examinations and a higher proportion in this group had deteriorated at the re-examination (fig 5). In the type 1-type 1 group the occurrence of symptoms was low in both examinations.

\section{ACTIVITY PATTERN}

The mean activity level did not change significantly between the examinations in the groups or between the groups (fig 5). More subjects in the type 2B-type 2B group were rated by the physician as having a low activity pattern during their leisure time. Hardly any of these subjects participated in educational or training activities and many showed a tendency to passivity at home and social isolation.

\section{PSYCHOMETRIC TESTS}

The type 2B-type 2B group deteriorated in their mean performance on the visuospatial test, block design (from stanine score 5 to stanine score 4 , $t=2 \cdot 19, p=0.02$ ) whereas their performance in perceptual speed, psychomotoric speed, and memory remained at a stable, low level (between stanine score 3 and 2). The type 1-type 1 group performed at about the same level in both examinations (close to stanine score 5 in all tests). The difference between groups in pattern of change between the examinations reached significance for the hold tests $(t=2 \cdot 76, \mathrm{p}=0.01)$.

\section{Discussion}

The results show that effects on the central nervous system due to long term exposure to solvents persist even if exposure has ceased. The most striking difference between the two groups at the second examination is the life histories. In the group with the diagnosis of solvent induced mild toxic encephalopathy (type 2B) more men had stopped working and were receiving sickness or early retirement pensions $(74 \% v 35 \%)$. The group also had reduced activity levels with regard to everyday life, leisure activities, education and training, and more neuropsychiatric symptoms.

A clinical follow up study of this type may have certain limitations due to a selection process operating before the patient's first contact with the clinic, workers with access to an industrial physician may be more likely to be referred to a clinic. The concern about adverse health effects of exposure to solvents among relatives and union representatives might persuade the worker to see a physician who refers him to the clinic. From this point of view it may not be possible to generalise the results of the clinical follow up study. There are also selection problems due to loss at follow up, since patients may have died or may not be willing to participate in the follow up study. In this study nine patients $(8 \%)$ were lost, of whom one had died, one had developed presenile dementia, and one could not be traced, whereas the others refused to participate in a second examination.

The diagnosis of solvent induced mild toxic encephalopathy (type 2B) in Sweden is based on an exposure criterion of at least ten years of exposure, on typical symptoms, and on pathological findings on the psychological function tests. The two groups (types 2B and 1) were comparable with regard to the results on the hold tests at the first examination. This indicates that their initial capacity was at about the same level. The differences in performance on the remaining tests could not be explained by differences in duration of exposure between the two groups or other diseases or the use of medication but may reflect individual susceptibility. When comparing the test results at the second examination it is worth noting that, on a group basis, the group of 28 people with the diagnosis of mild toxic encephalopathy (type 2B) had not deteriorated in tests indicating diffuse organic brain damage such as occurs in Altzheimer's disease and Pick's disease. They did, however, deteriorate on the verbal and reasoning tests between the two examinations, which appears merely to reflect a regression towards the mean, according to the analyses.

The chronic symptoms reported to be associated with long term exposure to solvents may be divided into core symptoms and other commonly associated symptoms. The core symptoms are increased fatigue, poor memory, difficulty in concentration, and per- 
sonality changes (emotional lability, depression). For some of these symptoms there are clear cut differences between the two groups, particularly with respect to depression, concentration, and lack of initiative. The report impairment of these symptoms in the type $2 \mathrm{~B}$ group is also in accordance with the evaluation made by the physician. The group with mild toxic encephalopathy (type 2B) was rated to have a more severe degree of depression and inactivity. These results might be due to exposure to organic solvents or because the worker had been classified as sick and encouraged to avoid exposure to solvents. At the clinics the routine has usually been to recommend the patients with suspected intoxication by solvents not to continue their exposure. Since many of these patients were older it is possible that society has not found it worth while to encourage re-education but has provided early retirement pensions. This will then lead to a situation' where the worker loses contact with fellow workers leading to isolation and, secondarily, a risk of depression and inactivity. Consequently, it might be claimed that part of the deterioration seen at the second examination might be iatrogenic. This view is strengthened by the fact that the non-working subjects in the type 1 group also felt symptomatically worse at follow up. It has also been suggested that development of symptoms may be explained by classic conditioning to substances with strong odours. ${ }^{25}$

An interesting point is that 12 men who, at first examination were diagnosed as having a solvent induced mild toxic encephalopathy (type 2B), did not receive this diagnosis at the second examination. One reason could be that they were wrongly diagnosed at the first examination because the psychometric tests were performed while the patient still had acute or subacute influence from the solvents. The recovery may then be explained by better hygiene at work and decreased exposure to solvents, consequently leading to smaller effects on the central nervous system.

There are some difficulties in comparing our results with those of other studies which have described the prognosis of patients with solvent induced neuropsychiatric disorders. The groups included in other studies vary considerably with respect to diagnostic criteria, sex distribution, age, and time of follow up and, consequently, the results are not fully consistent. With regard to the patients with mild toxic encephalopathy our results are partly consistent with other findings. Two Danish follow up studies concluded that reversibility is not observed nor is further progression to be expected if exposure is stopped. ${ }^{19} 20$ Finnish studies found that the clinical picture and test results six years after cessation of exposure could be worsened, unchanged, or improved. ${ }^{21} 22$ In a Swedish follow up examination after two to eight years without exposure, the patients' performance on psychometric tests was essentially unchanged. ${ }^{23}$ These authors, however, also reported a decrease in the mean number of symptoms whereas our study indicated that the subjects had slightly deteriorated symptomatically between the examinations. Taken together, the studies on prognosis show great individual differences, both in susceptibility to solvents and in prognosis of the disease. None, however, supports the view that a solvent induced mild toxic encephalopathy is a progressive disease comparable with presenile dementia such as Alzheimer's and Pick's diseases.

In the group with exposure and symptoms only (type 1) we found that in most subjects the symptoms of depression, difficulty in concentration, lack of initiative, and tiredness had improved. The subjects in this group were more active during their leisure time and all who worked at the first examination were still working at the re-examination. This indicates that if the worker is taken out of exposure when he is presenting symptoms without signs of impairment in intellectual functions, recovery is to be expected in most cases, even if exposure has lasted for years.

Emphasising the preventive aspects of occupational medicine it seems necessary to follow up solvent exposure workers closely with regard to symptoms such as increased fatigue, neuraesthenia, depressive complaints, and impaired memory. To detect early symptoms possibly indicative of incipient occupational solvent intoxication, some form of screening procedure is necessary. This procedure should preferably take the form of a periodic structured or semistructured interview with workers at risk. This approach would obviously focus on the symptomatology considered to be present in the solvent induced toxic encephalopathy. If interviewing each worker is not practical a self administered, validated questionnaire should be used. The specificity of this questionnaire, however, is likely to be low and the correlation between questionnaire scores and psychometric test results is not high. ${ }^{24}$ The purpose of the screening test is to select workers who should have priority for further investigation and evaluation. An overlap between symptoms of acute intoxication and those which might be part of the chronic syndrome is inevitable. The chronic syndrome must not be diagnosed solely on the basis of the results of a screening procedure. One further benefit of the type of screening procedure might be the identification of workplaces in which exposure appears excessive.

Another important question concerns the possibility of active rehabilitation. Some patients may benefit from cognitive behavioural therapy..$^{25}$ The results of this study suggest that part of the deterioration in symptoms may be due to the early retirement pensions and the accompanying social isolation. Adequate training of the functions affected and help 
in handling social situations might diminish or eliminate such symptoms.

This work was supported by the Swedish Work Environment Fund. We are gratefully indebted to $\mathrm{Dr}$ Monica Hane who contributed to the design of the study and to Owe Almqvist, Bengt Bengtsson, Birgitta Pålsson, and Ulf Åslund who contributed to the data collection.

1 Axelson $\mathrm{O}$, Hane $\mathrm{M}$, Hogstedt $\mathrm{C}$. A case-referent study on neuropsychiatric disorders among workers exposed to solvents. Scand J Work Environ Health 1976;3:14-20.

2 Mikkelsen S. A cohort study of disability pension and death among painters with regard to disabling presenile dementia as an occupational disease. Scand J Soc Med 1980;16:34-43S.

3 Olsen J, Sabroe S. A case-referent study of neuropsychiatric disorders among workers exposed to solvents in the Danish wood and furniture industry. Scand J Soc Med 1980;16: $34-49 S$.

4 Lindström K, Riihimäki H, Hänninen K. Occupational solvent exposure and neuropsychiatric disorders. Scand $J$ Work Environ Health 1984;10:321-3.

5 Hänninen $\mathrm{H}$, Eskelinen L, Husman $\mathrm{K}$, Nurminen $\mathrm{M}$. Behavioural effects of long-term exposure to a mixture of organic solvents. Scand J Work Environ Health 1976;2: $240-55$.

6 Hane M, Axelson O, Blume J, Hogstedt C, Sundell L, Ydreborg B. Psychological function changes among house painters. Scand J Work Environ Health 1977;3:91-9.

7 Knave B, Anselm-Olson B, Elofsson S, et al. Long-term exposure to jet fuel. II. A cross-sectional epidemiological investigation on occupationally-exposed industrial workers with special reference to the nervous system. Scand $J$ Work Environ Health 1978;4:19-45.

8 Elofsson SA, Gamberale F, Hindmarsh T, et al. Exposure to organic solvents. A cross sectional epidemiologic investigation on occupationally exposed car and industrial spray painters with special reference to the nervous system. Scand $J$ Work Environ Health 1980;6:239-73.

9 Lindström K, Wickström G. Psychological function changes among maintenance house painters exposed to low levels of organic solvents mixtures. Acta Psychiatr Scand 1983;67, (suppl) 303:81-91.

10 Linz DH, de Garmo PL, Morton WE, Wiens AN, Coull BM, Maricle RA. Organic solvent-induced encephalopathy in industrial painters. $J$ Occup Med 1986;28:119-25.

11 Baker EL, Letz RE, Eisen EA, et al. Neurobehavioral effects of solvents in construction painters. $J$ Occup Med 1988;30: 116-23.

12 Joint World Health Organisation/Nordic Council Ministers Working Group. Chronic effects of organic solvents on the central nervous system and diagnostic criteria. Copenhagen: WHO, 1985.

13 Cranmer JM, Golberg L, eds. Neurobehavioral effects of solvents. Neurotoxicology 1986;7:1-95.

14 National Institute for Occupational Safety and Health. Organic solvent neurotoxicity. Current Intelligence Bulletin 48; 1987:39.

15 Errebo-Enudsen EO, Olsen F. Organic solvents and presenile dementia (the painters' syndrome). A critical review of the Danish literature. Science of the Total Environment 1986; 48:45-67.

16 Grasso $P$, Sharratt $M$, Davies DM, Irvine D. Neurophysiological and psychological disorders and occupational exposure to organic solvents. Food and Chemical Toxicology 1984;22:819-52.

17 Flodin U, Edling C, Axelson O. Clinical studies of psychoorganic syndromes among workers with exposure to solvents. Am J Ind Med 1984;5:287-95.

18 Edling C. Nervous system symptoms and signs associated with long-term organic solvent exposure. In: Chronic effects of organic solvents on the central nervous system and diagnostic criteria. (Report of a Joint World Health Organisation/Nordic Council Ministers Working Group.) Copenhagen: WHO, 1985:149-55.

19 Bruhn P, Arlien-Soborg P, Gyldensted C, Christensen EL. Prognosis in chronic toxic encephalopathy: a two year followup study in 26 house painters with occupational encephalopathy. Acta Neurol Scand 1981;64:259-72.

20 Gregersen P. Neurotoxic effects of organic solvents in exposed workers: two controlled follow-up studies after 5.5 and 10.6 years. Am J Ind Med 1988;14:681-701.

21 Juntunen J, Antti-Poika M, Tola S, Partanen T. Clinical prognosis of patients with diagnosed chronic solvent intoxication. Acta Neurol Scand 1982;65:488-503.

22 Antti-Poika $M$. Overall prognosis of patients with diagnosed chronic organic solvent intoxication. Int Arch Occup Environ Health 1982;51:127-38.

23 Orbaeck P, Lindgren M. Prospective clinical and psychometric investigation of patients with chronic toxic encephalopathy induced by solvents. Scand J Work Environ Health 1988; 14:37-44.

24 Ekberg K, Hane M. Test battery for investigating functional disorders-the TUFF battery. Scand J Work Environ Health 1984;10:14-17S.

25 Bolla-Wilson $\mathrm{K}$, Wilson RJ, Bleecker ML. Conditioning of physical symptoms after neurotoxic exposure. J Occup Med 1988;30:684-86.

Accepted 5 May 1989 